\title{
Serum levels of polyamine synthesis Endocrine enzymes increase in diabetic patients with breast cancer
}

\author{
V Kenan Çelik', Sercan Kapancık1, Turgut Kaçan², Selen Baloglu Kaçan³, \\ Serkan Kapancık ${ }^{1}$ and Hasan Kılıçgün ${ }^{4}$ \\ ${ }^{1}$ Department of Biochemistry, Cumhuriyet University School of Medicine, Sivas, Turkey \\ ${ }^{2}$ Department of Medical Oncology, High Specialized Education and Research Hospital, Bursa, Turkey \\ ${ }^{3}$ Department of Internal Medicine, Afyonkarahisar State Hospital, Afyon, Turkey \\ ${ }^{4}$ Department of Nutrition and Dietetics, Health Science Faculty, University of Erzincan, Erzincan, Turkey
}

Correspondence

should be addressed

to $\mathrm{V}$ Kenan

Email

kenanim123@yahoo.com

\begin{abstract}
Background: In this study, it was aimed to investigate the relationship between diabetes and breast cancer and the detection of enzymes and ornithine levels in polyamine synthesis pathway in diabetes, breast cancer and diabetic breast cancer patients. Methods: Ornithine, arginine decarboxylase, ornithine decarboxylase and agmatinase levels have been measured in serum of all groups. Ornithine levels were measured spectrophotometrically. Arginine decarboxylase, ornithine decarboxylase and agmatinase levels were determined by ELISA kits.

Results: Except for the diabetic group, the levels of enzymes in the polyamine synthesis pathway were increased in all and statistically significant $(P<0.05)$. The increase in the levels of agmatinase was very important among the enzymes $(P<0.001)$.

Conclusions: Decreased levels of polyamine synthase enzymes in diabetes mellitus were found to be increased patients with breast cancer. Whether and how diabetes-based breast cancer development relates to increase activity of enzymes responsible for polyamine synthesis requires further mechanistic and prospective monitoring studies in larger patient cohorts.
\end{abstract}

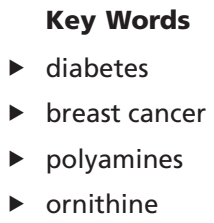

Endocrine Connections (2017) 6, 574-579

\section{Introduction}

In the seventh Diabetes Atlas of 2015 of The International Diabetes Federation (IDF), it is reported that one person in every 6 seconds in the world died of diabetes, 1 in 7 births is affected by gestational diabetes, 1 in every 11 adults has diabetes and this ratio will be increased $1 / 10$ in 2040. Type II diabetes, the most common form of diabetes, increases with changing cultural and social changes. Many years ago, breast cancer was found to be more common in diabetic patients (1). Subsequent studies suggested that there was a very serious link between cancer and diabetes, especially with type II diabetes $(2,3)$. It has been suggested that postmenopausal women over 50 years of age and older with diabetes have increased the risk of breast cancer by about 20-27\% (3). The International Agency for Research on Cancer (IARC) states that breast cancer, the most common among women, ranks second among all cancer types in the world. It was estimated that there were 1.67 million new cases (25\% of all cancer cases) in the world in 2012, and this figure is expected to approach 3 million by 2030 . Breast cancer is the fifth leading cause of death among the cancers, and it is predicted that in 2012, 522,000 patients with breast cancer have lost their lives. High metastatic and recurrence abilities of breast cancer the most common type of cancer seen among 


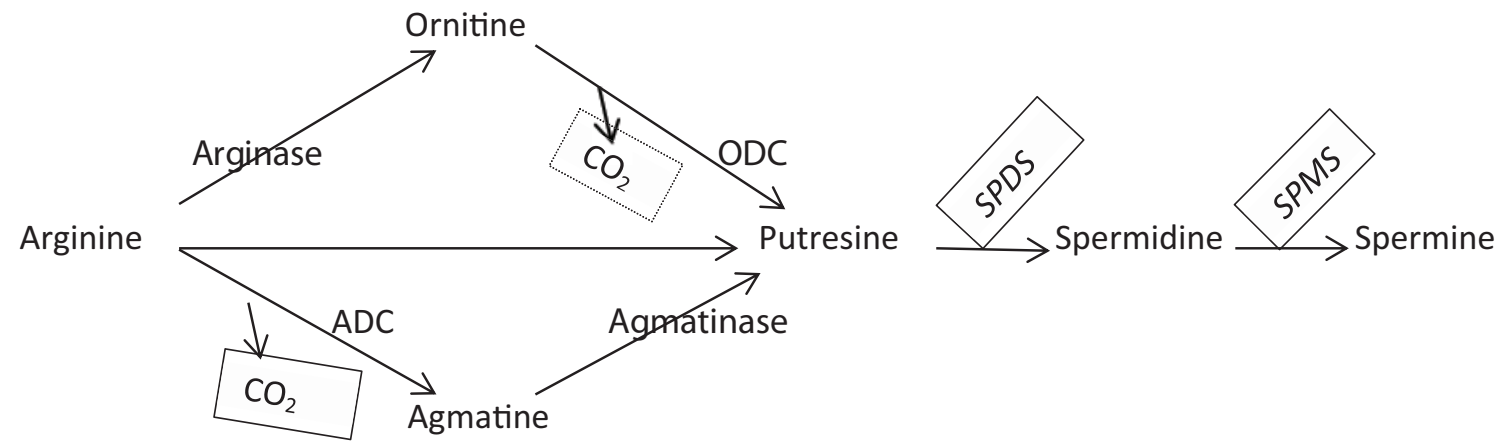

Figure 1

The pathway of polyamine synthesis. ADC, Arginine decarboxylase; ODC, Ornithine decarboxylase; SPDS, Spermidine synthase; SPMS, Spermine synthase.

women in the world, increase the risk of mortality (4, 5). Polyamines (putrescine, spermidine, spermine and agmatine) are positively charged aliphatic amines. As biological routers, polyamines interact with different macromolecules such as DNA, RNA and proteins and have the ability to regulate their biochemical activities. Polyamines direct cell proliferation by regulating mechanisms such as translation and transcription (6, $7,8)$. They also effective in many modulations such as post-transcriptional regulation, modulation of synaptic activity and modulation of ion channels that is part of the excitation network of neurons. Recent studies have clearly shown that polyamines affect many systems such as almost all ionotropic receptors (NMDA, Kainate, AMPA, $\mathrm{H}^{+}$) and $\mathrm{K}^{+}, \mathrm{Na}^{+}, \mathrm{Ca}^{2+}$ channels and thus play a central role in the formation of homeostatic response to the major depressive disorder (MDD) and stress (9). Intracellular and extracellular concentrations of polyamines are important in all these biological orientations. The amounts of polyamines are tightly regulated by the ornithine decarboxylase (ODC), a rate-limiting enzyme in the synthesis pathway, and another rate-limiting enzyme, spermidine/spermine N1-acetyltransferase 1 (SAT1), located in the degradation pathway (10). Therefore, changes in the concentrations of polyamines are associated with many diseases. Intracellularly elevated polyamine levels were associated with histone acetylation and deacetylation in normal and cancerous cells $(11,12)$. Gene promoters and inhibitors that are responsible for the regulation of many histone acetylases deacetylases are controlled by polyamines. These, respectively, polyamine-dependent protein kinase (13), tyrosine kinase (14), nuclear protein kinase NII (15), mammary gland polyamine-responsive protein kinase (16), self-phosphorylating polyamine-stimulated protein kinase (17) and casein kinase II (CKII) (18). All of them are regulated by polyamines. The putrescine, the precursor of spermidine and spermine molecules, is mainly synthesized from L-arginine by two different chemical reactions (Fig. 1). Regulation of the ODC, the rate-limiting enzyme in the synthesis pathway, is mediated by agmatine, which is synthesized from L-arginine via arginine decarboxylase (ADC) enzyme in the other pathway. Agmatine acts on the inhibitor effect on ODC via antizyme (AZ) molecule (19). Agmatine, which is synthesized as an endogenous polyamine and can be taken by diet, is destroyed by agmatinase to form putresin (20). Agmatine synthesis, mainly expressed in the hippocampus and cortex of the brain, is mainly found in glial astrocytes (21).

Studies on adipose tissue related to polyamines have shown that insulin receptor tyrosine kinase (IRTK) activity is influenced by physiological polyamines such as spermine which have similar effects with insulin (22, $23,24)$. Thus, it is suggested that polyamines may play an important role in the regulation of the mitogenic effect of insulin in breast cancer cells (25). Therefore, it is important to learn about the current status of the enzymes involved in the polyamine synthesis pathway between diabetes and breast cancer. It would be another important work to elucidate the relationship of enzymes to these diseases.

In the current study, we aimed to identify the enzymes such as ADC, ODC and agmatinase in the synthesis pathway of polyamines as well as the ornithine levels in serum of patients with diabetes, breast cancer and diabetic breast cancer and to reveal their relations in these diseases. http://www.endocrineconnections.org DOI: 10.1530/EC-17-0137
() 2017 The authors Published by Bioscientifica Ltd
This work is licensed under a Creative Commons Attribution-NonCommercial-NoDerivatives 4.0 International License. 
Table 1 The gender ranges of patients and controls.

\begin{tabular}{lccc}
\hline Gender & Control & & Patient \\
\cline { 1 - 2 } Male & 0 & & 0 \\
Total & 20 & 60 \\
Tomen & 20 & & 60
\end{tabular}

\section{Materials and methods}

\section{Patients and control group}

The 20 breast cancers with type II diabetes (group-1), 20 breast cancer patients (group-2) and 20 type 2 diabetes mellitus patients (group 3) who were made a diagnosis with breast cancer and applied to the Cumhuriyet University Medicine Faculty Oncology Policlinic were included in the study. It was not made restriction respect to the sex, age or the histopathologic type of cancer as well as its degree. Our control group was provided from the 20 healthy individuals (group-4), who do not have any systemic diseases (diabetes, hypertension, cancer disease). There was no significant difference observed between gender in the patient groups and control group (Table 1).

The study was approved by the local research committee for ethics (Cumhuriyet University clinical research ethic committee, Decision No: 2016-01/16). All subjects were informed about the study and written consent was obtained from each one.

\section{Blood samples collection}

Blood samples were taken from the controls and patients who were diagnosed with breasts cancer or/and diabetes mellitus and did not receive any therapy. The serums were obtained by centrifugation at $1610 \mathrm{~g}$ for $10 \mathrm{~min}$, and the blood samples were preserved in $-80^{\circ} \mathrm{C}$ for further study.

Ornithine, arginine decarboxylase, ornithine decarboxylase and agmatinase levels have been measured
Table 2 The age ranges of patients and controls.

Groups
Group 1 (Breast cancer with diabetes) $(n=20)$
Group 2 (Breast cancer) $(n=20)$
Group 3 (Tip II diabetes) $(n=20)$
Group 4 (Control) $(n=20)$
$P$

\begin{tabular}{c} 
Age $(\mathrm{X} \pm \mathrm{S})$ \\
\hline $57 \pm 7$ \\
$56 \pm 8$ \\
$52 \pm 5$ \\
$53 \pm 6$ \\
$P=0.074$
\end{tabular}

Data expressed as mean \pm s.D.

in serum of all groups. Ornithine level was calculated spectrophotometrically at $515 \mathrm{~nm}$ using the method defined by Chinard and was reported as $\mu \mathrm{mol} / \mathrm{mL}$ (26). Arginine decarboxylase, ornithine decarboxylase and agmatinase levels were determined by ELISA kit according to the manufacturer's protocol (Cusabio Biotech, Wuhan, China) and expressed as $\mathrm{pg} / \mathrm{mL}$.

\section{Statistical analysis}

In the evaluation of the data, when the parametric test assumptions were fulfilled, the analysis of variance and the Tukey test were applied, and when the parametric test assumptions were not fulfilled, the Kruskal-Wallis test and Mann-Whitney $U$ test were applied. The data are stated in the tables as the arithmetical average \pm standard deviation, and the level of significance was taken as 0.05 .

\section{Results}

When the age ranges of the individuals in the control group were compared with the age ranges of the individuals in the patients groups, there was no significant difference observed between age in the control group and patient groups $(P>0.05)$ (Table 2$)$. When the levels of enzymes (ADC, ADC and agmatinase) in the synthesis pathway of polyamines were compared to the control group, it was

Table 3 The serum ornithine, arginine decarboxylase, ornithine decarboxylase and agmatinase levels in patients and controls.

\begin{tabular}{|c|c|c|c|c|c|c|c|c|}
\hline & \multicolumn{2}{|c|}{ Arginine decarboxylase $(\mathrm{pg} / \mathrm{mL})$} & \multicolumn{2}{|c|}{ Agmatinase $(\mathrm{pg} / \mathrm{mL})$} & \multicolumn{2}{|c|}{ Ornithine decarboxylase $(\mathrm{pg} / \mathrm{mL})$} & \multicolumn{2}{|c|}{ Ornithine $(\mu \mathrm{mol} / \mathrm{mL})$} \\
\hline & $\bar{X} \pm$ S.D. & Median & $\bar{X} \pm$ S.D. & Median & $\bar{X} \pm$ S.D. & Median & $\bar{X} \pm$ S.D. & Median \\
\hline Group $1(n=20)$ & $114 \pm 56$ & 77 & $55 \pm 21$ & 43 & $60 \pm 40$ & 56 & $0.13 \pm 0.0$ & 0.1 \\
\hline Group $2(n=20)$ & $91 \pm 20$ & 84 & $48 \pm 13$ & 49 & $58 \pm 9$ & 56 & $0.14 \pm 0.0$ & 0.1 \\
\hline Group $3(n=20)$ & $61 \pm 23$ & 60 & $33 \pm 10$ & 31 & $33 \pm 20$ & 31 & $0.13 \pm 0.0$ & 0.1 \\
\hline Group $4(n=20)$ & $67 \pm 12$ & 67 & $35 \pm 12$ & 36 & $44 \pm 18$ & 37 & $0.10 \pm 0.0$ & 0.1 \\
\hline$P$ & \multicolumn{2}{|c|}{$<0.05$} & \multicolumn{2}{|c|}{$<0.01$} & \multicolumn{2}{|c|}{$<0.05$} & \multicolumn{2}{|c|}{$<0.05$} \\
\hline
\end{tabular}

*This table is based on the arithmetic mean values obtained from the Kruskal-Wallis- $H$ test for each group ( \pm standard deviation and median). Group 1= Breast Cancer with Type II Diabetes; Group 2=Breast Cancer; Group 3=Type II Diabetes; Group 4=Control. 
seen that enzyme levels increased in all groups except for the diabetes group. Ornithine levels increased in the whole patient group compared to the control. All results were statistically significant (Table 3).

\section{Discussion}

In this study, enzymes (ADC, ODC and agmatinase) and ornithine levels in the pathway of polyamine synthesis were studied in patients with diabetes, breast cancer and diabetic breast cancer. According to our findings, when all enzymes levels in the patient groups were compared to the control group, it was seen that except for diabetic group, all enzyme levels in the other patient groups were increased. Ornithine levels were the same in the patient groups but increases in levels according to the control group were statistically significant (Table 3 ). The available results show us that the synthesis pathway is active, which may lead to an increase in the concentration of major polyamines (putresin, spermidine and spermine), as well as increase the consumption of the precursor arginine amino acid. Studies showing that changes in arginine metabolism are important in a variety of diseases such as sepsis, cancer and type II diabetes also support our findings $(27,28,29)$. In another study supporting our findings, it was suggested that arginine/ornithine ratio (AOR) decreased in breast cancer patients and this could be a marker (30). The ornithine levels in all of the study groups were increased and statistically significant (Table 3). Increased ornithine levels may also underpin the development of osmotic stress by causing an increase in osmolarity (31). The most striking difference in the diabetes group is the reduction in ODC levels, the rate-limiting enzyme in the polyamine synthesis pathway. However, the ADC enzyme level did not change when compared to the control, this led to an increase in ornithine levels (Table 3 ). The decrease in the ODC level (about 25\% relative to the control) indicates that polyamine synthesis also decreases. In one study, insulin-stimulated tyrosine kinase (IRTK) activity stimulated by insulin was shown to be activated by Mg2+, spermine and spermidine in the absence of insulin (32), and other studies have shown that polyamines in adipose tissue cells effect on lipid and glucose metabolism like insülin $(22,23,24)$. According to our findings, decreased polyamine synthesis also affects spermine and spermidine concentrations; thus, a suspicion raises that it causes insulin resistance in type II diabetes as well. For this to be clear, there is a need for further work in the much broader type II diabetic groups. On the other hand, an increase in ADC, agmatinase, ODC and ornithine levels in the polyamine synthesis pathway were found in breast cancer and diabetic breast cancer patients. When the values in Table 3 are examined, according to the control group, $\mathrm{ADC}=172 \%$, Agmatinase $=157 \%$ and $\mathrm{ODC}=139 \%$ were increased in breast cancer patients, while $\mathrm{ADC}=136 \%$, Agmatinase $=134 \%$ and $\mathrm{ODC}=135 \%$ were increased in diabetic based breast cancer patients compared to the control group. If the levels of synthesis enzymes involved in the synthesis of polyamines are compared to the diabetic group, it can be seen that ADC $=147 \%$, Agmatinase $=142 \%$, ODC $=182 \%$ were increased in breast cancer. In diabetes-based breast cancer, this ratio was $\mathrm{ADC}=186 \%, \quad$ Agmatinase $=166 \%, \quad \mathrm{ODC}=187 \%$, consecutively. The difference is very significant when it is based on diabetes. Although an increase in the levels of polyamines in cancer appears to be a natural result (30, 33, $34)$, an increase in the levels of enzymes responsible for polyamine synthase pathway in breast cancer developing in the presence of diabetes is a significant finding.

Studies on polyamines have shown that polyamines are induced in response to many physico-biochemical stresses such as osmolarity, reactive oxygen species (ROS), including memory and learning modulation (35). Therefore, increasing and decreasing concentrations of polyamines play a role in the pathogenesis of many diseases $(31,36,37,38)$. For this reason, according to our findings, there is a clear statement that the levels of polyamines will tend to decrease in diabetes and increase in the breast cancer. At the end of the first time since the discovery of agmatine (more than 100 years ago), many features have been discovered. Thus, restoration of impaired polyamine homeostasis in the treatment of complex diseases such as diabetes mellitus, neurotrauma and neurodegenerative diseases, substance abuse, cognitive disorders and cancer, which are inadequately clinically required for treatment, is a new hope in the treatment of diseases $(39,40)$.

In conclusion, our study is important for the first-time detection of polyamine synthesis pathway in diabetes, breast cancer and diabetic breast cancer patients and to make comparisons in each group. The results of the study clearly show that polyamine homeostasis is impaired. This is a finding that can be effective in diagnosis of the development and progression of both diabetes and breast cancer. What benefit does diabetes mellitus have in terms of its treatment when the reduced polyamines are replaced will be revealed by the work to be done in the future. http://www.endocrineconnections.org DOI: 10.1530/EC-17-0137
(๔) 2017 The authors Published by Bioscientifica Ltd
This work is licensed under a Creative Commons Attribution-NonCommercial-NoDerivatives 4.0 International License. 
On the other hand, after decreased levels of polyamine in diabetes mellitus, an increasing level of polyamine before breast cancer development may be an important forerunner for catching breast cancer formation. Detection and follow-up at regular intervals of the levels of enzymes responsible for the polyamine synthesis pathway in female patients with diabetes can give us the chance to catch breast cancer early. Additional work to be done in this regard may provide important benefits in the early diagnosis and treatment of the disease.

An increasing level of polyamine before breast cancer development may be an important marker for catching breast cancer formation. Detection and follow-up at regular intervals of the levels of enzymes responsible for the polyamine synthesis pathway in female patients with diabetes can give us the chance to catch breast cancer early. Additional work to be done in this regard may provide important benefits in the early diagnosis and treatment of the disease.

\section{Declaration of interest}

The authors declare that there is no conflict of interest that could be perceived as prejudicing the impartiality of the research reported.

\section{Funding}

This research did not receive any specific grant from any funding agency in the public, commercial or not-for-profit sector.

\section{References}

1 Glicksman AS \& Rawson RW. Diabetes and altered carbohydrate metabolism in patients with cancer. Cancer 19569 1127-1134. (doi:10.1002/1097-0142(195611/12)9:6<1127::AIDCNCR2820090610>3.0.CO;2-4)

2 Hardefeldt PJ, Edirimanne S \& Eslick GD. Diabetes increases the risk of breast cancer: a meta-analysis. Endocrine-Related Cancer 201219 793-803. (doi:10.1530/ERC-12-0242)

3 Boyle P, Boniol M, Koechlin A, Robertson C, Valentini F, Coppens K, Fairley LL, Boniol M, Zheng T, Zhang Y, et al. Diabetes and breast cancer risk: a meta-analysis. British Journal of Cancer $2012 \mathbf{1 0 7}$ 1608-1617. (doi:10.1038/bjc.2012.414)

4 Torre LA, Bray F, Siegel RL, Ferlay J, Lortet-Tieulent J \& Jemal A. Global cancer statistics, 2012. CA 201565 87-108.

5 Steeg PS. Targeting metastasis. Nature Reviews Cancer 201616 201-218. (doi:10.1038/nrc.2016.25)

6 Henderson CM, Anderson CB \& Howard MT. Antisense-induced ribosomal frameshifting. Nucleic Acids Research $2006344302-4310$. (doi:10.1093/nar/gkl531)

7 Umekage S \& Ueda T. Spermidine inhibits transient and stable ribosome subunit dissociation. FEBS Letters $2006 \mathbf{5 8 0} 1222-1226$. (doi:10.1016/j.febslet.2006.01.033)

8 Dayoub R, Thasler WE, Bosserhoff AK, Singer T, Jauch KW, Schlitt HJ $\&$ Weiss TS. Regulation of polyamine synthesis in human hepatocytes by hepatotrophic factor augmenter of liver regeneration. Biochemical and Biophysical Research Communications 2006345 181-187. (doi:10.1016/j.bbrc.2006.04.040)
9 Limon A, Mamdani F, Hjelm BE, Vawter MP \& Sequeira A. Targets of polyamine dysregulation in major depression and suicide: activity-dependent feedback, excitability, and neurotransmission. Neuroscience and Biobehavioral Reviews 201666 80-91. (doi:10.1016/j. neubiorev.2016.04.010)

10 Pegg AE. Mammalian polyamine metabolism and function. IUBMB Life 200961 880-894. (doi:10.1002/iub.230)

11 D'agostino L \& Di Luccia A. Polyamines interact with DNA as molecular aggregates. European Journal of Biochemistry 2002269 4317-4325. (doi:10.1046/j.1432-1033.2002.03128.x)

12 Hobbs CA, Paul BA \& Gilmour SK. Deregulation of polyamine biosynthesis alters intrinsic histone acetyltransferase and deacetylase activities in murine skin and tumors. Cancer Research 200262 67-74.

13 Keuhn GD \& Atmar VJ. New perspectives on polyamine-dependent protein kinase and the regulation of ornithine decarboxylase by reversible phosphorylation. Advance Polyamine Research 19834 615-630.

14 Khan NA, Masson I, Quemener V, Clari G, Moret V \& Moulinoux JP. Polyamines and polyamino acids regulation of cytosolic tyrosine protein (Tyr-P) kinase from human erythrocytes. Biochemistry International 199020 863-868.

15 Hara T, Takahashi K \& Endo H. Reversal of heparin inhibition of nuclear protein kinase NII by polyamines and histones. FEBS Letters 1981128 33-36. (doi:10.1016/0014-5793(81)81072-1)

16 Criss WE. A review of polyamines and cancer. Turkish Journal of Medical Sciences 200333 195-205.

17 Morishita Y, Watanabe K, Akogyeram C, Deu B \& Criss WE. Calmodulin stimulates polyamine-responsive protein kinase in the absence of Ca2+. Biochimica et Biophysica Acta (BBA)-General Subjects 1983755 352-357. (doi:10.1016/0304-4165(83)90237-4)

18 Gündoğuş-Özcanlı N, Sayılır C \& Criss WE. Effects of polyamines polyamine synthesis inhibitors, and polyamine analogs on casein kinase II using Myc oncoprotein as substrate. Biochemical Pharmacology 199958 251-254. (doi:10.1016/S0006-2952(99)00084-2)

19 Kim SW, Mangold U, Waghorne C, Mobascher A, Shantz L, Banyard J $\&$ Zetter BR. Regulation of cell proliferation by the antizyme inhibitor: evidence for an antizyme-independent mechanism. Journal of Cell Science 2006119 2583-2591. (doi:10.1242/jcs.02966)

20 Sastre M, Regunathan S, Galea E \& Reis DJ. Agmatinase activity in rat brain: a metabolic pathway for the degradation of agmatine. Journal of Neurochemistry 199667 1761-1765. (doi:10.1046/j.14714159.1996.67041761.x)

21 Regunathan S, Feinstein DL, Raasch W \& Reis DJ. Agmatine (decarboxylated arginine) is synthesized and stored in astrocytes. Neuroreport 19956 1897-1900. (doi:10.1097/00001756-19951002000018)

22 Lockwood DH \& East LE. Studies of the insulin-like actions of polyamines on lipid and glucose metabolism in adipose tissue cells. Journal of Biological Chemistry 1974249 7717-7722.

23 Olefsky JM. Comparison of the effects of insulin and insulin-like agents on different aspects of adipocyte metabolism. Hormone and Metabolic Research 197911 209-213. (doi:10.1055/s-0028-1092709)

24 Richelsen B, Pedersen SB \& Hougaard DM. Characterization of antilipolytic action of polyamines in isolated rat adipocytes. Biochemical Journal 1989261 661-665. (doi:10.1042/bj2610661)

25 Huber M \& Poulin R. Permissive role of polyamines in the cooperative action of estrogens and insulin or insulinlike growth factor I on human breast cancer cell growth. Journal of Clinical Endocrinology and Metabolism 199681 113-123. (doi:10.1210/jcem.81.1.8550737)

26 Chinard FP. Photometric estimation of proline and ornithine. Journal of Biological Chemistry 1952199 91-95.

27 Moinard C, Breuillard C \& Charrueau C. L-Arginine metabolism Impairment in sepsis and diseases: causes and consequences. In L-Arginine in Clinical Nutrition, pp 145-158. Berlin, Germany: Springer International Publishing, 2017.

28 Lind DS. Arginine and cancer. Journal of Nutrition 2004134 2837S-2841S. 
29 Tessari P, Cecchet D, Cosma A, Puricelli L, Millioni R, Vedovato M \& Tiengo A. Insulin resistance of amino acid and protein metabolism in type 2 diabetes. Clinical Nutrition 201130 267-272. (doi:10.1016/j. clnu.2011.02.009)

$30 \mathrm{Hu}$ L, Gao Y, Cao Y, Zhang Y, Xu M, Wang Y, Jing Y, Guo S, Jing $\mathrm{F}, \mathrm{Hu} \mathrm{X}$, et al. Identification of arginine and its "Downstream" molecules as potential markers of breast cancer. IUBMB Life $2016 \mathbf{6 8}$ 817-822. (doi:10.1002/iub.1557)

31 Celik VK, Ersan EE, Kilicgun H, Kapancik S \& Ersan S. Agmatine mediated hypertonic stress development in Schizophrenia: a Novel study. Neuropsychiatry 20166 184-189. (doi:10.4172/ Neuropsychiatry.1000138)

32 Paxton R \& Ye L. Regulation of heart insulin receptor tyrosine kinase activity by magnesium and spermine. Molecular and Cellular Biochemistry 2005277 7-17. (doi:10.1007/s11010-005-5755-4)

33 Thomas T \& Thomas TJ. Polyamine metabolism and cancer. Journal of Cellular and Molecular Medicine 20037 113-126. (doi:10.1111/j.1582-4934.2003.tb00210.x)

34 Kawakita M, Hiramatsu K, Yanagiya M, Doi Y \& Kosaka M. Determination of N1, N12-diacetylspermine in urine: a novel tumor marker. Methods in Molecular Biology 2011720 367-378.
35 Guerra GP, Rubin MA \& Mello CF. Modulation of learning and memory by natural polyamines. Pharmacological Research 2016112 99-118. (doi:10.1016/j.phrs.2016.03.023)

36 Stephenson AH, Christian JF \& Seidel ER. Polyamines regulate eukaryotic initiation factor $4 \mathrm{E}$ binding protein 1 gene transcription. Biochemical and Biophysical Research Communications 2004323 204-212. (doi:10.1016/j.bbrc.2004.08.076)

37 Childs AC, Mehta DJ \& Gerner EW. Polyamine-dependent gene expression. Cellular and Molecular Life Sciences 200360 1394-1406. (doi:10.1007/s00018-003-2332-4)

38 Kapancik S, Celik VK, Kilickap S, Kacan T \& Kapancik S. The relationship of agmatine deficiency with the lung cancer. International Journal of Hematology and Oncology 201626 103-109. (doi:10.4999/ uhod.160971)

39 Piletz JE, Aricioglu F, Cheng JT, Fairbanks CA, Gilad VH, Haenisch B, Halaris A, Hong S, Lee JE, Li J, et al. Agmatine: clinical applications after 100 years in translation. Drug Discovery Today 201318 880-893. (doi:10.1016/j.drudis.2013.05.017)

40 Shopsin B. The clinical antidepressant effect of exogenous agmatine is not reversed by parachlorophenylalanine: a pilot study. Acta Neuropsychiatry 201325 113-118. (doi:10.1111/j.1601-5215.2012.00675.x)

Received in final form 11 August 2017

Accepted 4 September 2017

Accepted Preprint published online 4 September 2017 http://www.endocrineconnections.org DOI: 10.1530/EC-17-0137
(C) 2017 The authors Published by Bioscientifica Ltd 